\title{
Does the Degree of Maternal Fever in the Setting of Chorioamnionitis Lead to Adverse Neonatal Outcomes?
}

\author{
Megan S. Varvoutis, MD, MS ${ }^{1}$ Azza E. Abdalla, MD² Sarah K. Dotters-Katz, MD, MMHPE \\ ${ }^{1}$ Department of OB/GYN, West Virginia University, Morgantown, \\ West Virginia \\ 2 Division of Maternal Fetal Medicine, Department of Obstetrics and \\ Gynecology, Duke University, Durham, North Carolina \\ Address for correspondence Megan S. Varvoutis, MD, Division of \\ Maternal Fetal Medicine, Department of Obstetrics and Gynecology, \\ Duke University, 2608 Erwin Road no. 200, Durham, NC 27705 \\ (e-mail: megvarvoutis@gmail.com).
}

AJP Rep 2022;12:e58-e63.

\begin{abstract}
Keywords

- chorioamnionitis

- intra-amniotic infection

- neonatal outcome

- maternal fever

Objective The effect of the degree of maternal fever in the setting of chorioamnionitis on neonatal morbidity is unclear. The objective of this study is to assess the association between high maternal fevers $\left(\geq 39^{\circ} \mathrm{C}\right)$ on neonatal morbidity.

Study Design Secondary analysis of Maternal-Fetal Medicine Units (MFMU) Cesarean Registry data obtained from 1999 to 2002 among singleton gestations with chorioamnionitis. Women with a temperature less than $39^{\circ} \mathrm{C}$ (low fever) compared with those with greater than or equal to $39^{\circ} \mathrm{C}$ (high fever). Primary outcome was a composite of adverse neonatal outcomes such as death, sepsis, necrotizing enterocolitis, grade-3 or -4 intraventricular hemorrhage, seizure within 24 hours of delivery, intubation within 24 hours of delivery, and requiring cardiopulmonary resuscitation. Demographic characteristics compared using Fisher's exact and Wilcoxon's rank-sum test as appropriate. Multivariate logistic regression analysis with performed to control for cofounders. Stratified analysis also performed to assess outcomes in term infants.

Results Of 1,313 included women, 1,200 (91.3\%) were in the low fever group and 113 $(8.7 \%)$ were in the high fever group. Women in the high fever group were more likely to be African American and group B Streptococcus positive. No difference in primary outcome was noted between the groups (38.9\% high fever vs. 35.8\% low fever, $p=0.54)$. High maternal fever was associated with increased risk of NICU admission ( 48.1 vs. $50.4 \%, p=0.02$ ). When controlling for African American race, preterm birth, and delivery route, patients with high fever were not more likely to have adverse neonatal outcomes (adjusted odds ratio $[\mathrm{aOR}]=1.28$, 95\% confidence interval $[\mathrm{Cl}]$ : $0.84,1.98)$. In the analysis limited to term infants, when controlling for confounders, high fever, similarly, was not associated with increased odds of adverse neonatal outcomes $(\mathrm{aOR}=1.59,95 \% \mathrm{Cl}: 0.96,2.65)$.

Conclusion The degree of maternal fever does not appear to be associated with an increased likelihood of adverse neonatal outcomes. Better understanding maternal factors that affect neonatal morbidity in the setting of chorioamnionitis is critical.
\end{abstract}

received

February 29, 2020 accepted after revision October 8, 2021
DOI https://doi.org/ 10.1055/s-0041-1742269. ISSN 2157-6998.

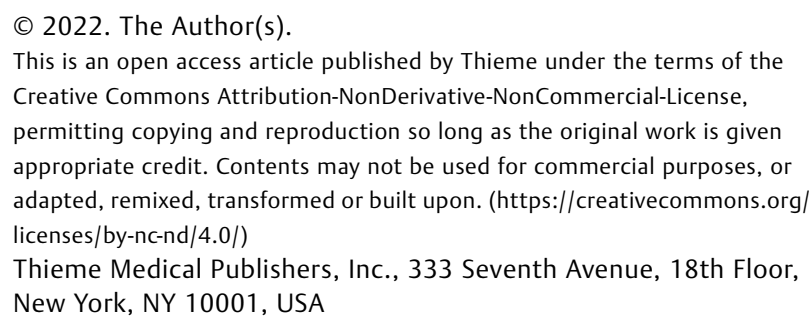
appropriate credit. Contents may not be used for commercial purposes, or adapted, remixed, transformed or built upon. (https://creativecommons.org/ licenses/by-nc-nd/4.0/) Thieme Medical Publishers, Inc., 333 Seventh Avenue, 18th Floor, New York, NY 10001, USA 


\section{Key Points}

- High maternal fever in the setting of chorioamnionitis does not appear to have an increased likelihood of adverse neonatal outcomes.

- It is important to identify factors that may increase the risk of adverse outcomes such as early onset sepsis.

- Maternal fever may not be a strong indicator for neonatal outcomes and antibiotic protocols.

Chorioamnionitis, also known as intra-amniotic infection (IAI), occurs in approximately 1 to $4 \%$ of all births in the United States and is associated with serious maternal and perinatal adverse outcomes. Approximately 12 to $13 \%$ of cesarean deliveries are affected by chorioamnionitis. ${ }^{1}$ IAI is typically caused by ascending polymicrobial bacterial infection in the setting of rupture of membranes; however, it can occur in the setting of intact amniotic membranes, although this is far-less common. ${ }^{2}$ Chorioamnionitis is caused by multiple microorganisms, often including the genital mycoplasmas Ureaplasma urealyticum and Mycoplasma hominis. ${ }^{3}$ Other organisms associated with chorioamnionitis include Gardnerella vaginalis, group B Streptococcus, and Escherichia coli which are commonly part of vaginal and enteric flora, respectively. ${ }^{3-7}$

Chorioamnionitis has been shown to increase risk of adverse maternal outcomes such as cesarean delivery, postpartum hemorrhage, endometritis, and wound infection. In rare instances, patients can develop sepsis, adult respiratory distress syndrome, and ultimately death., 7,8 Adverse fetal outcomes associated with chorioamnionitis include fetal death, neonatal sepsis, intraventricular hemorrhage (IVH), cerebral white matter damage, and long-term disability. ${ }^{9}$ Preterm infants are at higher risk of these complications than term infants. ${ }^{9,10}$ Clinical findings of intrauterine amniotic infection include maternal fever, fetal tachycardia ( $>160$ beats per minute), uterine fundal tenderness, and purulent or foul-smelling amniotic fluid. Although low-grade fever can be transient in labor, maternal fever greater than $100.4^{\circ} \mathrm{F}$ warrants further evaluation. ${ }^{11,12}$ Additionally, we know that maternal IAI negatively impacts neonatal outcomes, particularly in term infants.

In most instances, the presence of maternal fever and at least one other sign, in the absence of other etiologies, is required to make a diagnosis of clinical chorioamnionitis. ${ }^{12,13}$ Previous older definitions included maternal tachycardia which has since been dropped from the definition of IAI. ${ }^{13}$ Isolated maternal fever has been shown to have adverse neonatal outcomes, as well as including lower 1-minute Apgar's scores, and neonatal oxygen requirement; this effect is more prevalent with higher degree of fever. ${ }^{14} \mathrm{~A}$ better understanding of the relationship between these clinical findings in the setting of chorioamnionitis on adverse maternal and neonatal outcomes is needed to better counsel patients on maternal and neonatal risks. The objective of this study was to assess the impact of high maternal fever $\left(\geq 39^{\circ} \mathrm{C}\right)$ in the setting of chorioamnionitis on neonatal morbidity.

\section{Materials and Methods}

We performed a secondary analysis of the Maternal-Fetal Medicine Units (MFMU) Cesarean Registry. ${ }^{15}$ The original
MFMU Cesarean Registry was created with the primary purpose of evaluating factors that influence the likelihood of a successful vaginal birth after cesarean (VBAC) after 1 prior cesarean section. Inclusion criteria for this large multicenter prospective observational study included women with one prior cesarean with term-singleton pregnancies (known low transverse scar or unknown scar) undergoing trial of labor.

Inclusion criteria for this analysis include women with a diagnosis of chorioamnionitis, (as defined by the original study as: clinical diagnosis of chorioamnionitis with an elevated body temperature). Presence of maternal and fetal tachycardia, uterine tenderness, and malodorous fluid were collected; however, these variables were not released with the deidentified dataset. The diagnosis of chorioamnionitis was made clinically by the provider. Exclusion criteria include multiple gestations, stillbirths, and patients with missing infection or delivery data. The MFMU Cesarean Registry dataset was built by trained study nurses who reviewed all available medical records of 14,529 women from 19 academic centers. Data regarding demographics, obstetric and medical history, and intrapartum events was collected from 1999 to 2002. Receipt of prenatal care was

Table 1 Maternal demographics

\begin{tabular}{|c|c|c|c|}
\hline Characteristics & $\begin{array}{l}\text { Maternal } \\
\text { temperature } \\
39^{\circ} \mathrm{C} \\
n=1,200(\%)\end{array}$ & $\begin{array}{l}\text { Maternal } \\
\text { temperature } \\
\geq 39^{\circ} \mathrm{C} \\
n=113(\%)\end{array}$ & $p$-Value \\
\hline $\begin{array}{l}\text { Maternal age (y) } \\
\text { Median (IQR) }\end{array}$ & $29(23,33)$ & $28(23,32)$ & 0.36 \\
\hline No prenatal care & $68(5.7)$ & $2(2.9)$ & 0.08 \\
\hline African American Race & $409(34.1)$ & $54(47.8)$ & $<0.01$ \\
\hline Public insurance & $614(51.2)$ & $60(53.1)$ & 0.77 \\
\hline Prior vaginal delivery & $382(32.2)$ & $31(27.7)$ & 0.34 \\
\hline $\begin{array}{l}\text { Pregnancy history of } \\
\text { pyelonephritis }\end{array}$ & $17(4.3)$ & $3(7.1)$ & 0.43 \\
\hline $\begin{array}{l}\text { Pregnancy history of } \\
\text { urinary tract infection }\end{array}$ & $151(38.0)$ & $17(40.5)$ & 0.74 \\
\hline $\begin{array}{l}\text { Pregnancy history of } \\
\text { vaginal infection }\end{array}$ & $184(15.3)$ & $19(16.8)$ & 0.68 \\
\hline $\begin{array}{l}\text { Maternal chronic } \\
\text { hypertension }\end{array}$ & $22(1.8)$ & $2(1.8)$ & $>0.99$ \\
\hline Maternal diabetes & $96(8.0)$ & $7(6.2)$ & 0.59 \\
\hline \multicolumn{4}{|l|}{ Substance use } \\
\hline Tobacco & $162(13.5)$ & $12(10.6)$ & 0.47 \\
\hline Alcohol & $49(4.1)$ & $3(2.7)$ & 0.62 \\
\hline Drugs & $69(5.8)$ & $2(1.8)$ & 0.81 \\
\hline
\end{tabular}

Abbreviation: IQR, interquartile range. 
defined by the original study as having two or more prenatal visits, not including visits to the emergency room. This study was considered exempt from the Institutional Review Board (IRB; identifier no.: Pro00057547).

\section{Statistical Analysis}

Chorioamnionitis was clinically identified and maximum maternal temperature was then defined as the exposure of interest. Women with maximum maternal temperature of less than $39^{\circ} \mathrm{C}$ (low maternal temperature) are classified as controls. Cases were defined as women with maximum maternal temperature greater than or equal to $39^{\circ} \mathrm{C}$ (high maternal temperature; - Table 2). Demographic characteristics compared using Fisher's exact and Wilcoxon's rank-sum test as appropriate. The primary outcome was an adverse neonatal composite score composed of death, confirmed/presumed neonatal sepsis, necrotizing enterocolitis, grade-3 or -4 intraventricular hemorrhage (IVH), neonatal seizure, neonatal intubation within 24 hours, and need for neonatal cardiopulmonary resuscitation (CPR). Secondary outcomes included neonatal intensive care unit (NICU) admission, median NICU length of stay, neonatal respiratory distress, and delivery arterial cord gas less than 7.10 (-Table 3).
Multivariate logistic regression was performed to adjust for potential confounding factors using backward stepwise regression with variables with $p$-value less than 0.2 , remaining in the final model to predict factors associated successful VBAC. Confounding variables in this model included body mass index, gestational age, fetal sex, African American race, oxytocin use, operative delivery, labor length, and antibiotic administration. A second planned regression was performed, stratifying patients into term and preterm deliveries. Confounding variables in these models included maternal body mass index (BMI) at delivery, fetal sex, African American race, oxytocin use, operative delivery, antibiotic administration and labor length. $p$-Values and adjusted odds ratios (aORs) are reported. Analyses were performed using Stata software (Version 14.0; Stata Corporation LLC, College Station, TX).

\section{Results}

Of the 14,529 women included in the original MFMU Cesarean Registry Study, 1,313 women met inclusion criteria. In the study cohort, 1,200 (91.4\%) women with chorioamnionitis had maternal temperature less than $39^{\circ} \mathrm{C}$ (low fever)

Table 2 Labor and delivery characteristics

\begin{tabular}{|c|c|c|c|}
\hline Characteristic & $\begin{array}{l}\text { Maternal temperature } \\
<39^{\circ} \mathrm{C} \\
n=1,200 \\
n(\%) / \text { median }(\mathrm{IQR})\end{array}$ & $\begin{array}{l}\text { Maternal temperature } \\
\geq 39^{\circ} \mathrm{C} \\
n=113 \\
n(\%) / \text { median (IQR) }\end{array}$ & $p$-Value \\
\hline Median gestational age at delivery (wk) & $39(32.7,40.3)$ & $39.2(36.1,40.3)$ & 0.51 \\
\hline BMI at delivery & $32.0(28.6,36.4)$ & $31.6(27.7,36.4)$ & 0.29 \\
\hline Preterm birth $(<37 \mathrm{wk})$ & $402(33.5)$ & $31(27.3)$ & 0.21 \\
\hline Fetal congenital anomaly & $37(3.1)$ & $3(2.7)$ & $>0.99$ \\
\hline Pregnancy related hypertension & $54(4.5)$ & $9(8.0)$ & 0.11 \\
\hline Median admission white blood cell count $\left(\times 10^{9} / \mathrm{L}\right)$ & $11.6(9.4,15.1)$ & $11(9,14.1)$ & 0.19 \\
\hline Male fetus & $608(50.7)$ & $67(59.3)$ & 0.09 \\
\hline Median duration of labor (h) & $13.4(7.9,22.1)$ & $14.2(7.4,24)$ & 0.67 \\
\hline Median duration of ruptured membranes (h) & $11.3(6.7,20.6)$ & $10.1(6.7,18.5)$ & 0.29 \\
\hline Use of Foley's balloon ripening & $27(2.3)$ & $2(1.8)$ & $>0.99$ \\
\hline Labor/IOL & $1,077(89.8)$ & $102(90.3)$ & $>0.99$ \\
\hline Oxytocin & $626(52.2)$ & $68(60.2)$ & 0.12 \\
\hline Epidural use & $871(75.7)$ & $87(80.6)$ & 0.29 \\
\hline GBS positive (treated) & $227(19.7)$ & $9(8.3)$ & 0.003 \\
\hline Exposed to intrapartum Abx & $1,098(91.5)$ & $103(91.2)$ & 0.86 \\
\hline Ampicillin and gentamicin & $431(35.9)$ & $43(38.1)$ & \multirow[t]{3}{*}{0.687} \\
\hline Clindamycin and gentamicin or cephalosporin/gentamicin & $370(30.8)$ & $37(32.7)$ & \\
\hline Partial or other regimen & $399(33.3)$ & $33(32.9)$ & \\
\hline Meconium stained fluid & $263(21.9)$ & $32(28.3)$ & 0.13 \\
\hline Operative vaginal delivery & $103(8.6)$ & $12(12.4)$ & 0.17 \\
\hline Cesarean & $685(57.1)$ & $60(53.1)$ & 0.43 \\
\hline
\end{tabular}

Abbreviations: Abx, antibiotics; BMI, body mass index; GBS, group B Streptococcus; IOL, induction of labour; IQR, interquartile range. 
Table 3 Adverse neonatal outcomes

\begin{tabular}{|c|c|c|c|}
\hline Characteristic & $\begin{array}{l}\text { Maternal } \\
\text { temperature } \\
<39^{\circ} \mathrm{C} \\
n=1,200 \\
n(\%) / \text { median } \\
(\mathrm{IQR})\end{array}$ & $\begin{array}{l}\text { Maternal } \\
\text { temperature } \\
\geq 39^{\circ} \mathrm{C} \\
n=113 \\
n(\%) / \text { median } \\
(\mathrm{IQR})\end{array}$ & $p$-Value \\
\hline Neonatal composite & $429(35.8)$ & 44 (38.9) & 0.54 \\
\hline Death & $52(4.5)$ & $3(2.9)$ & 0.62 \\
\hline $\begin{array}{l}\text { Confirmed or presumed } \\
\text { sepsis }\end{array}$ & $399(33.3)$ & $42(37.2)$ & 0.41 \\
\hline Necrotizing enterocolitis & $28(2.3)$ & $3(2.7)$ & 0.75 \\
\hline Grade-3 or -4 IVH & $31(2.6)$ & $1(0.9)$ & 0.52 \\
\hline Seizure with 24 hours & $23(2.0)$ & $2(1.9)$ & 1.00 \\
\hline $\begin{array}{l}\text { Required intubation } \\
\text { within } 24 \text { hours }\end{array}$ & $25(2.1)$ & $3(2.7)$ & 0.73 \\
\hline Required CPR & $25(2.1)$ & $3(2.7)$ & 0.73 \\
\hline \multicolumn{4}{|l|}{ Secondary outcomes } \\
\hline NICU admission & $577(48.1)$ & $57(50.4)$ & 0.69 \\
\hline Median NICU LOS (d) & $10(4,32)$ & $7(4,20)$ & 0.09 \\
\hline Respiratory distress & $249(20.8)$ & $19(16.8)$ & 0.39 \\
\hline Cord gas $<7.10$ & $32(2.7)$ & $7(6.2)$ & 0.07 \\
\hline
\end{tabular}

Abbreviations: CRP, C-reactive protein; IQR, interquartile range; IVH, intraventricular hemorrhage; LOS, length of stay; NICU, neonatal intensive care unit.

and $113(8.6 \%)$ had a maternal temperature greater than or equal to $39^{\circ} \mathrm{C}$ (high fever).

Women with low fever were more likely to be of African American race ( 34.1 vs. $47.8 \%, p<0.01$ ). No other significant differences were noted between the groups ( - Table $\mathbf{1}$ ). Additionally, no significant differences were noted in mean gestational age at delivery ( 39 vs. 39.2 weeks, $p=0.51$ ), maternal BMI at delivery ( 32.0 vs. 31.9 weeks, $p=0.29$ ), or preterm delivery ( 33.5 vs. $27.3 \%, p=0.21$ ). The length of labor (13.4 vs. $14.2 \mathrm{~h}, p=0.67$ ) or rupture of membranes (11.3 vs. $10.1, p=0.29$ ) was not significantly different either.

A total of 429 (35.8\%) of women with low fever and 44 (38.9\%) with high fever had adverse neonatal outcome, as previously defined, $(p=0.54)$. Similarly, no significant differences in the individual composite components were noted, ( - Table 3 ). After stratifying by term and preterm gestational age, no significant differences were seen in the adverse neonatal outcomes for term infants (23.6 vs. 30.2\%, $p=0.19$ ) or in preterm infants (66.7 vs. $66.7 \%, p>0.99$ ) deliveries. However, among term deliveries, a significantly higher rate of NICU admission occurred in women with high fevers ( 33.0 vs. $45.4 \%, p=0.02$ ). In term deliveries, 8 infants had confirmed sepsis and 188 had presumed sepsis out of 196 infants in the primary composite. In preterm deliveries, the opposite was true, women with high fevers had a significantly lower NICU admission rate (86.7 vs. 66.7, $p=0.01 ;$ - Table 4).

When controlling for confounders, high fever was not associated with a significant difference in neonatal outcomes
Table 4 Adverse neonatal outcome: stratified gestational age by term and preterm

\begin{tabular}{|c|c|c|c|}
\hline \multirow[t]{2}{*}{ Characteristic } & \multicolumn{2}{|c|}{$\begin{array}{l}\text { Women with } \\
\text { chorioamnionitis } \\
n(\%) / \text { median (IQR) }\end{array}$} & \multirow[t]{2}{*}{$p$-Value } \\
\hline & $\begin{array}{l}\text { Maternal } \\
\text { temperature } \\
<39^{\circ} \mathrm{C}\end{array}$ & $\begin{array}{l}\text { Maternal } \\
\text { temperature } \\
\geq 39^{\circ} \mathrm{C}\end{array}$ & \\
\hline \multicolumn{4}{|l|}{$\begin{array}{l}\text { Gestational age } \\
\geq 37 \text { weeks }(n=947)\end{array}$} \\
\hline \multicolumn{4}{|l|}{ Primary outcome } \\
\hline & $n=798$ & $n=82$ & \\
\hline Composite & $203(23.6)$ & $26(30.2)$ & 0.19 \\
\hline Death & $2(0.23)$ & 0 & $>0.99$ \\
\hline $\begin{array}{l}\text { Confirmed or } \\
\text { presumed sepsis }\end{array}$ & $171(21.4)$ & $25(30.5)$ & 0.23 \\
\hline \multicolumn{4}{|l|}{ Secondary outcome } \\
\hline NICU admission & $284(33.0)$ & $39(45.4)$ & 0.02 \\
\hline Median NICU LOS (d) & $5(4,8)$ & $5(4,8)$ & 0.81 \\
\hline Cord gas $<7.10$ & $29(3.4)$ & $5(5.8)$ & 0.23 \\
\hline \multicolumn{4}{|l|}{$\begin{array}{l}\text { Gestational age } \\
<37 \text { weeks }(n=433)\end{array}$} \\
\hline \multicolumn{4}{|l|}{ Primary outcome } \\
\hline & $n=402$ & $n=31$ & \\
\hline Composite score & $226(66.7)$ & $18(66.7)$ & $>0.99$ \\
\hline Death & $50(16.8)$ & $3(15.8)$ & $>0.99$ \\
\hline $\begin{array}{l}\text { Confirmed or } \\
\text { presumed sepsis }\end{array}$ & $200(59.0)$ & $17(63.0)$ & 0.84 \\
\hline \multicolumn{4}{|l|}{ Secondary outcomes } \\
\hline NICU admission & $293(86.4)$ & $18(66.7)$ & 0.01 \\
\hline Median NICU LOS (d) & $35(18,74)$ & $54(22,111)$ & 0.12 \\
\hline Cord gas $<7.10$ & $3(0.88)$ & $2(7.41)$ & 0.05 \\
\hline
\end{tabular}

Abbreviations: IQR, interquartile range; LOS, length of stay; NICU, neonatal intensive care unit.

(aOR $=1.26 ; 95 \%$ confidence interval $[\mathrm{Cl}]: 0.78,2.02$ ). In the analysis stratified by gestational age at delivery, high fever was not associated with adverse neonatal outcomes in term or in preterm deliveries $(\mathrm{aOR}=1.59,95 \% \mathrm{CI}$ : 0.96 , 2.65 ; - Table 5).

\section{Discussion}

In this study, maternal temperature greater than or equal to $39^{\circ} \mathrm{C}$ was not associated with adverse neonatal outcomes in the setting of chorioamnionitis, even when stratifying by gestational age at delivery. However, in term infants with IAI, higher maternal fever was associated with higher rates of NICU admission.

It is clear that chorioamnionitis is a significant risk factor for early-onset sepsis (EOS). What aspects of the IAI impact that risk are less well-defined. Other authors have studied the impact of maternal fever to be a significant risk factor for 
Table 5 Unadjusted and adjusted analysis of association of maternal temperature $\geq 39$ with adverse neonatal outcomes for infants by gestational age at delivery

\begin{tabular}{|l|l|l|}
\hline & OR $(95 \% \mathrm{CI})$ & aOR $(95 \% \mathrm{CI})$ \\
\hline All comers & $1.15(0.77,1.7)$ & $1.28(0.84,1.98)^{\mathrm{a}}$ \\
\hline$\geq 37$ weeks & $1.65(1.01,2.71)$ & $1.59(0.96,2.65)^{\mathrm{b}}$ \\
\hline$<37$ weeks' EGA & $0.81(0.38-1.69)$ & $0.88(0.41,1.85)^{\mathrm{b}}$ \\
\hline
\end{tabular}

Abbreviations: aOR, adjusted odds ratio; $\mathrm{Cl}$, confidence interval; $\mathrm{EGA}$, estimated gestational age; OR, odds ratio.

Note: Final $n$ for each multivariable model as follows: $<37$ weeks $(n=433)$ and $\geq 37$ weeks $(n=880)$.

${ }^{a}$ Controlled for maternal body mass index (BMI) at delivery, gestational age, fetal sex, African American race, oxytocin use, operative delivery, antibiotic administration, labor length.

${ }^{b}$ Controlled for maternal BMI at delivery, fetal sex, African American race, oxytocin use, operative delivery, antibiotic administration, and labor length.

neonatal sepsis. ${ }^{16}$ In a nested case-control study of 340 women delivering at more than or equal to 34 weeks, Puopolo et al found a linear relationship between degree of fever and risk of EOS. This study also found longer duration of membrane rupture to be associated linearly with risk of EOS. Due to low numbers of confirmed EOS in our study, the primary outcome is focused on a composite of adverse neonatal outcomes, and not EOS alone, which might explain the difference in the results.

Empiric treatment of neonates born to women with IAI has been routinely recommended in treatment algorithms from the American Association of Pediatrics, the Center for Disease Control and Prevention, and the National Institute for Health and Care Excellence. ${ }^{17,18}$ However, more recently, in an attempt to limit use of empiric antibiotics, another recent guideline differentiates neonatal treatment recommendations based on clinical neonatal appearance and isolated fever versus suspected or confirmed IAI. ${ }^{19}$ A new risk-based approach was recently developed by Kaiser Permanente, using multivariable prediction models, to estimate the risk of EOS and provide suggested treatment algorithms. This model includes degree of maternal fever, time of ruptured membranes, and antibiotic administration. ${ }^{20}$ Comparison of treatment algorithms based on the National Institute for Health and Care Excellence (NICE) guidelines for empiric treatment versus risk-based treatment guided by the Kaiser sepsis risk calculator found a relative reduction in empiric antibiotic use of $74 \%$ without missed cases of EOS. ${ }^{21}$ Towers et al calculated the rate of intrapartum fever $\left(>38^{\circ} \mathrm{C}\right.$ ) at approximately $6.8 \%$ and the number needed to treat as $412 .{ }^{22}$ As the Kaiser sepsis risk calculator uses maternal fever as a variable in risk assessment, further study is needed to better understand the relationship between high maternal fever and neonatal outcomes, beyond the very rare outcome of confirmed EOS.

\section{Strengths and Limitations}

Our study has notable strengths. It is one of the first to evaluate whether maternal fever is an independent risk factor for neonatal outcomes. We were able to control for many cofounders as data were collected by a trained research team and provides good accuracy and consistency to our secondary analysis. The administration and type of antibiotic administered for treatment of chorioamnionitis was also evaluated in our secondary analysis. This variable is crucial, as it has been previously shown to be an important component of multivariate risk assessment models for early onset neonatal sepsis. ${ }^{16,20}$

Our study also has several limitations. The secondary analysis was performed on women undergoing TOLAC which may not be generalizable to a larger population. The definition of chorioamnionitis used by the MFMU Cesarean Registry was based on clinical diagnosis, not using the new IAI definition given the timeframe of the study. ${ }^{13}$ Additionally, we were limited by the lack of released data regarding the diagnostic criteria. Thus, some women diagnosed with chorioamnionitis in the study may not meet the current IAI definition. ${ }^{13}$ With the current definition of IAI, some of our control group could have been classified as isolated maternal fever if the risk factor for chorioamnionitis was initially maternal tachycardia. Additionally, there is not a diagnostic confirmation of chorioamnionitis by either amniotic fluid culture or gram stain and/or placental pathology, though this is not something routinely used in clinical management. The type of antibiotic was collected in the Cesarean Registry, but we were not able to control for duration of therapy in the current study.

\section{Conclusion}

Identifying risk factors for adverse neonatal outcomes can provide additional information to guide postnatal assessment and treatment. Our study sought to evaluate the independent effect of degree of maternal fever. Interestingly, prior studies have shown increased degree of maternal fever to be a significant risk factor for neonatal sepsis. However, in our study, the degree of maternal fever was not significantly associated with adverse neonatal outcome or sepsis alone. Reevaluating the impact of IAI and adverse neonatal outcomes may prove to be different as definitions have changed. Further studies to better identify and confirm true risk factors for adverse neonatal outcomes will better help guide neonatal management and treatment.

\section{Funding}

None.

Conflict of Interest

None declared.

\section{References}

1 Gibbs RS, Duff P. Progress in pathogenesis and management of clinical intraamniotic infection. Am J Obstet Gynecol 1991;164(5, pt. 1):1317-1326

2 Goldenberg RL, Andrews WW, Hauth JC. Choriodecidual infection and preterm birth. Nutr Rev 2002;60(5, pt. 2):S19-S25 
3 Eschenbach DA. Ureaplasma urealyticum and premature birth. Clin Infect Dis 1993;17(Suppl 1):S100-S106

4 Anderson BL, Simhan HN, Simons KM, Wiesenfeld HC. Untreated asymptomatic group B streptococcal bacteriuria early in pregnancy and chorioamnionitis at delivery. Am J Obstet Gynecol 2007;196(06):524.e1-524.e5

5 Soper DE, Mayhall CG, Dalton HP. Risk factors for intraamniotic infection: a prospective epidemiologic study. Am J Obstet Gynecol 1989;161(03):562-566, discussion 566-568

6 Fahey JO. Clinical management of intra-amniotic infection and chorioamnionitis: a review of the literature. J Midwifery Womens Health 2008;53(03):227-235

7 Newton ER, Piper J, Peairs W. Bacterial vaginosis and intraamniotic infection. Am J Obstet Gynecol 1997;176(03):672-677

8 Yoon BH, Romero R, Moon JB, et al. Clinical significance of intraamniotic inflammation in patients with preterm labor and intact membranes. Am J Obstet Gynecol 2001;185(05):1130-1136

9 Gomez R, Romero R, Ghezzi F, Yoon BH, Mazor M, Berry SM. The fetal inflammatory response syndrome. Am J Obstet Gynecol 1998;179(01):194-202

10 Gotsch F, Romero R, Kusanovic JP, et al. The fetal inflammatory response syndrome. Clin Obstet Gynecol 2007;50(03):652-683

11 Newton ER. Chorioamnionitis and intra-amniotic infection. Clin Obstet Gynecol 1993;36(04):795-808

12 Dashe JS, Rogers BB, McIntire DD, Leveno KJ. Epidural analgesia and intrapartum fever: placental findings. Obstet Gynecol 1999; 93(03):341-344

13 Committee on Obstetric P. Committee Opinion No. Committee opinion no. 712: intrapartum management of intra-amniotic infection. Obstet Gynecol 2017;130(02):e95-e101

14 Lieberman E, Lang J, Richardson DK, Frigoletto FD, Heffner LJ, Cohen A. Intrapartum maternal fever and neonatal outcome. Pediatrics 2000;105(1, pt. 1):8-13
15 Landon MB, Leindecker S, Spong CY, et al; National Institute of Child Health and Human Development Maternal-Fetal Medicine Units Network. The MFMU Cesarean Registry: factors affecting the success of trial of labor after previous cesarean delivery. Am J Obstet Gynecol 2005;193(3, pt. 2):1016-1023

16 Puopolo KM, Draper D, Wi S, et al. Estimating the probability of neonatal early-onset infection on the basis of maternal risk factors. Pediatrics 2011;128(05):e1155-e1163

17 Sahni M, Franco-Fuenmayor ME, Shattuck K. Management of late preterm and term neonates exposed to maternal chorioamnionitis. BMC Pediatr 2019;19(01):282

18 Antibiotics for Early-Onset Neonatal Infection: Evidence Update June 2014: A Summary of Selected New Evidence Relevant to NICE Clinical Guideline 149 "Antibiotics for Early-Onset Neonatal Infection: Antibiotics for the Prevention and Treatment of Early-Onset Neonatal Infection" (2012). London, United Kingdom: National Institute for Health and Care Excellence; 2014

19 Higgins RD, Saade G, Polin RA, et al; Chorioamnionitis Workshop Participants. Evaluation and management of women and newborns with a maternal diagnosis of chorioamnionitis: summary of a workshop. Obstet Gynecol 2016;127(03):426-436

20 Kuzniewicz MW, Puopolo KM, Fischer A, et al. A quantitative, riskbased approach to the management of neonatal early-onset sepsis. JAMA Pediatr 2017;171(04):365-371

21 Goel N, Shrestha S, Smith R, et al. Screening for early onset neonatal sepsis: NICE guidance-based practice versus projected application of the Kaiser Permanente sepsis risk calculator in the UK population. Arch Dis Child Fetal Neonatal Ed 2020;105(02): $118-122$

22 Towers CV, Yates A, Zite N, Smith C, Chernicky L, Howard B. Incidence of fever in labor and risk of neonatal sepsis. Am J Obstet Gynecol 2017;216(06):596.e1-596.e5 